\title{
EMPREENDEDORISMO CULTURAL NA LITERATURA: UMA EXPERIÊNCIA COLABORATIVA
}

Luiz Eduardo Kogut ${ }^{1}$

Fernando Antonio Prado Gimenez ${ }^{2}$

\footnotetext{
${ }^{1}$ Universidade Federal do Paraná - Campus Avançado de Jandaia do Sul

${ }^{2}$ Departamento de Administração Geral e Aplicada / Setor de Ciências Sociais Aplicadas / Universidade Federal do Paraná
} 


\section{EMPREENDEDORISMO CULTURAL NA LITERATURA: UMA EXPERIÊNCIA COLABORATIVA}

Resumo: O estudo do empreendedorismo cultural ainda se apresenta como uma área difusa e de diversas interpretações. O uso do termo "empreendedor cultural" é um pouco polêmico. Para alguns, este apresenta um caráter negativo ao associar a cultura a negócios. Para outros, no entanto, é possível usá-lo para a descrição de atividades artísticas e culturais sem nenhuma restrição. Esse artigo analisou elementos do empreendedorismo cultural presentes em entrevista dada pela diretora do festival literário Londrix. A curta fala da diretora foi lida e serviu como ponto inicial para enxergar quais elementos de gestão foram utilizados na criação e direção do festival, assim como quais foram as especificidades da sua trajetória histórica e de sua administração e como elas existem dentro do universo de estudo do empreendedorismo cultural. Os resultados indicaram algumas dimensões importantes do fenômeno: forte viés colaborativo, busca por recursos, parcerias público-privadas e a preocupação com questões sociais e institucionais.

Palavras-chave: Cultura; Empreendedorismo cultural. Literatura. Economia Criativa.

\section{$1 \quad$ Introdução}

O estudo do empreendedorismo cultural ainda se apresenta como uma área difusa e de diversas interpretações. A maioria dos autores, ao citar o tema, não especifica qual abordagem irá utilizar (ALBINSSON, 2017), sendo que as abordagens podem ser muito diversas. Albinsson (2017) resume essa problemática em duas abordagens possíveis: uma focada no desenvolvimento das artes e, a outra, na forma que antropólogos e economistas institucionais usam o termo. A primeira abordagem se trata de enxergar o empreendedorismo presente na dinâmica da produção cultural dentro de uma economia. Já a segunda faz uso do termo "cultura" como o agregado para tudo o que se produz dentro de uma sociedade, então o empreendedorismo cultural se trata de como esse agregado de uma cultura influencia o empreendedorismo e como o empreendedorismo pode influenciar a sociedade como um todo.

Nesse artigo, haverá um foco maior na primeira abordagem, ou seja, na abordagem que identifica o empreendedorismo dentro da produção de um bem, serviço ou carreira dentro do universo dos produtos culturais. Esses produtos culturais podem incluir os mais diversos setores, desde produções cinematográficas, museus, turismo, músicas, teatro, literatura e todo 
o ecossistema existente em volta dessas produções - eventos, espetáculos, festivais e afins. Essa abordagem visa enxergar como o trabalho no âmbito cultural, muitas vezes marcado pela inovação artística, necessita também englobar elementos de gestão para tornar esse trabalho possível. Essa gestão existe no gerenciamento de todos os elementos englobados pela produção cultural, desde a captação e gerenciamento de recursos, até a aplicação desses recursos e a forma em que o produto toma forma e chega ao consumidor.

Há, então, a necessidade desse conhecimento relacionado à administração e gestão de ativos para a simples existência do empreendimento cultural. Partindo de visões sobre o empreendedorismo, o empreendedor cultural pode muito bem ser visto como um empreendedor dentro das mais diversas ópticas. Segundo Schumpeter (1911), o empreendedor não seria apenas o gestor e criador de um negócio, mas também aquele que inova dentro das dinâmicas apresentadas. Partindo do principio da inovação artística, presente na figura 1, que apresenta os aspectos principais do estudo do empreendedorismo cultural, o artista que, além de gerir sua produção cultural, também inova artisticamente, apresenta todas as características chaves para ser um empreendedor a partir dos escritos de Schumpeter - porém apenas aqueles que praticam a inovação artística. Essa visão que, de certa forma, limita o alcance da definição de empreendedorismo cultural é partilhada por autores como Klamer (2011), que afirma que o empreendedor cultural é apenas aquele que busca, como resultado final, a produção cultural. Que os elementos econômicos envolvidos nessa produção devem ser apenas um meio para a realização cultural, e não seu objetivo.

Figura 1: Aspectos do empreendedorismo cultural 


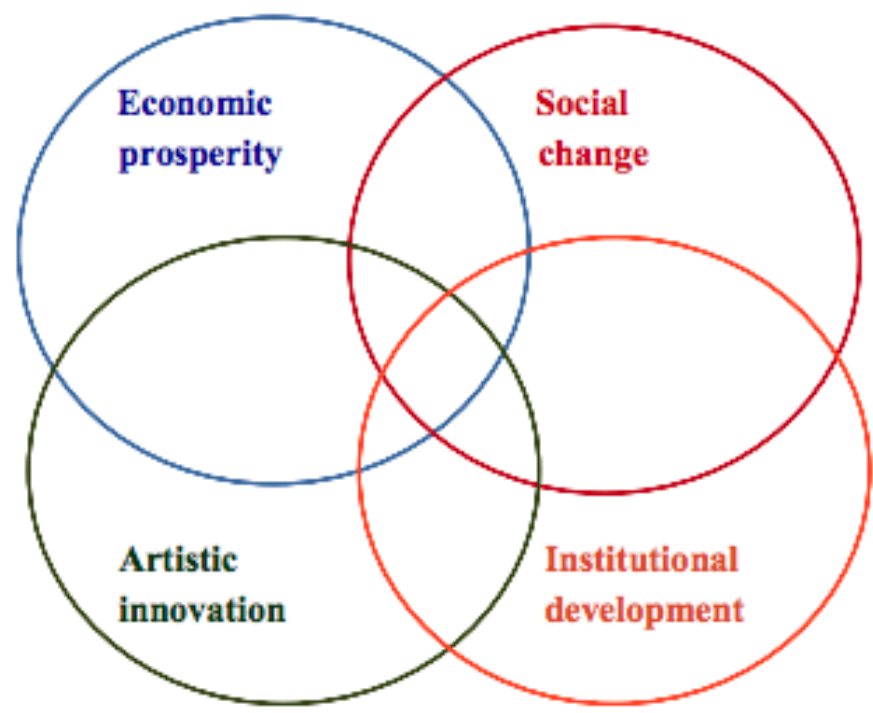

Fonte: Albinsson, 2017

Porém, essa visão é constantemente relativizada, muitas vezes sendo referenciada como um empreendedor artístico, e não necessariamente um cultural. O empreendedor cultural é, acima de tudo, um ator na crescente valorização de uma economia cultural (ELLMEIER, 2003), agindo na produção para atender a nova demanda por bens e serviços de valor simbólico, muitas vezes atendendo demandas específicas e cumprindo funções específicas dentro de uma espécie de indústria cultural, que engloba toda a produção. Essa é uma visão contrária à de Klamer, pois não envolve necessariamente a cultura como objetivo final, como é o caso de empreendimentos como redes de cinema. Porém, é uma dinâmica que age conforme preceitos schumpeterianos de empreendedorismo e concorrência: em um universo em que o verdadeiro empreendedor é um inovador que gera imitadores e seguidores, um artista inovador também irá gerar atores semelhantes, que nem sempre existirão com objetivo de novas inovações ou com o objetivo final a geração da cultura, mas que farão parte dessa indústria cultural, talvez a partir da identificação de uma oportunidade produtiva, e farão a gestão de seu empreendimento.

No texto, também serão usados preceitos da abordagem antropológica do empreendedorismo cultural, principalmente os presentes na figura 1: a mudança social e o desenvolvimento institucional. Segundo os teóricos que fazem uso dessa abordagem, o empreendedorismo cultural parte e tem como resultado final o ambiente social e institucional 
a sua volta. Assim, o empreendedor cultural é aquele que, ao empreender, faz uso dos elementos da sua própria cultura. Autores como Lounsbury e Glynn (2001) defendem, por exemplo, o papel do storytelling para o empreendedor, como forma de tornar legítimo, inspirar e fazer seu empreendimento funcionar, a partir de elementos da cultura. Ou seja, o empreendedor iria usar elementos da sua cultura como mecanismos para dar forma ao seu empreendimento - seja em termos de investimentos, seja em termos culturais. Já Lipartito (1998) apresenta o outro espectro, como o empreendimento pode ter origem de questões altamente culturais a um espaço específico para, por fïm, trazer mudanças sociais profundas. Essas mudanças sociais também se apresentam no último aspecto da figura 1 , o desenvolvimento institucional que ocorre a partir do empreendimento e a partir da mudança de paradigma que os empreendedores culturais podem fazer surgir.

A partir desse referencial teórico e das esferas de estudo apresentadas, esse artigo visa analisar elementos do empreendedorismo cultural presentes em uma entrevista dada por Chris Viana, diretora do festival literário Londrix, à Folha de Londrina, disponível no canal do YouTube do jornal ${ }^{1}$. A curta fala de Chris será lida e servirá como ponto inicial para enxergar quais elementos de gestão foram utilizados na criação e direção do festival, assim como quais foram as especificidades da sua trajetória histórica e de sua administração e como elas existem dentro do universo de estudo do empreendedorismo cultural.

\section{Empreendedorismo Cultural}

Estudos sobre empreendedorismo podem ser focados em inúmeros contextos. Um dos contextos que tem atraído a atenção em tempos recentes é o da Economia Criativa. Entre as razões que justificam tal atenção, salientam-se duas: o potencial de contribuição para o desenvolvimento socioeconômico presente nas atividades da economia criativa; e, os aspectos específicos das organizações deste setor que as diferenciam de outros setores de atividade (BENDASSOLLI et al, 2009; DALLA COSTA; SOUZA-SANTOS, 2011; KIRSCHBAUM et al, 2009; MACHADO, 2009).

Disponível
https://www.youtube.com/watch?v=Vk3B1GMYwLs\&list=PLQgJvn0

Disponível em https://www.youtube.com/watch?v=Vk3B1GMYwLs\&list=PLQgJvn04KXksQ3JolANkFBUNGdZzYYhJV\&index=13 
Dentro da denominada economia criativa, há um elenco heterogêneo de empreendimentos. Todavia, a maior parte destes inclui-se no campo da denominada economia da cultura ou economia cultural (BENDASSOLLI; WOOD JÚNIOR, 2010; BRAGA, 2015). É o caso, por exemplo, da literatura, teatro, música, circo, cinema e artes plásticas, entre outros.

No campo dos estudos da economia cultural, podem ser encontrados estudos e pesquisas focados no empreendedorismo cultural (HAUSMANN; HEINZE, 2016). No entanto, este é um campo ainda embrionário, em especial no Brasil. Gimenez (2017) indicou que o primeiro artigo publicado em periódico brasileiro sobre empreendedorismo cultural surgiu há apenas 13 anos (DE MARCHI, 2006). Por outro lado, na língua inglesa, Dimaggio (1982a; 1982b) são as referências mais antigas que abordaram o tema do empreendedorismo cultural, em busca feita na Web of Science.

O uso do termos "empreendedor cultural" e "empreendedorismo cultural" é um pouco polêmico. Para alguns, este apresenta um caráter negativo ao associar a cultura a negócios. Para outros, no entanto, é possível usar estes termos para a descrição de atividades artísticas e culturais sem nenhuma restrição.

No primeiro lado da questão, por exemplo, Oliveira (2015) salientou os riscos do uso desses termos quando associados exclusivamente a uma perspectiva econômica. Para o autor, este uso pode significar "um estágio em que a cultura deixa de ser contraponto ou “instrumento neutro de práticas mercadológicas" para se tornar terreno determinante do mundo dos negócios, ela mesma como grande negócio" (OLIVEIRA, 2015, p. 247-248).

De forma igualmente crítica, Braga (2015) apontou que:

\begin{abstract}
é forçoso reconhecer que é extremamente difícil estabelecer focos de resistência aos modelos de negócio e às formas de comportamento ativadas pelas instituições destinadas a promover o empreendedorismo e a inovação em cultura. No entanto, é absolutamente urgente repensar o modelo sobre o qual são construídas as indústrias culturais e criativas, demonstrando os limites dos discursos oficiais, enquanto se imaginam outras formas de relação com o campo cultural e a promoção da cultura e das artes (p. 233).
\end{abstract}

Bendassolli e Wood Júnior (2010) apresentaram estudo sobre carreiras na indústria criativa. Vinte artistas de diferentes setores de atividades culturais da cidade de São Paulo foram indagados sobre as competências necessárias para a carreira artística. Apenas um usou 
o termo empreendedorismo, indicando uma pouca relevância de competências ou de identidades empreendedoras para os participantes do estudo. As menções mais frequentes referiram-se a talento, ascetismo, cognição e comunicação.

Por outro lado, há estudos que defendem a ideia de que uma identidade empreendedora tenha espaço na economia da cultura. Por exemplo, Enhuber (2014), ao comentar a trajetória de Damien Hirst, artista inglês que teve papel central na reurbanização do leste de Londres, apontou como é difícil distinguir os conceitos de empreendedor cultural e econômico. Outro estudo (CORÁ, 2016), sugere uma forte aproximação entre o empreendedorismo econômico e cultural, ao comentar sobre as trajetórias de dois artistas brasileiros. Em seu estudo, a autora abordou estratégias, construção discursiva sobre o valor do empreendimento e práticas culturais como recursos para o empreendimento. Para ela:

tais empreendedores só se tornaram referência nos setores artísticos em que atuam por serem artistas consagrados e, sobretudo, por serem visionários na construção de produtos culturais inovadores e que se tornam diferenciais no mercado cultural e artístico, tornando-os fonte de inspiração estética e de modelo de gestão (p. 87).

Gangi (2017) sugeriu que há um consenso inicial entre os estudiosos do empreendedorismo nas artes de que, assim como no empreendedorismo de negócios, empreender envolve processos de criação, comunicação, entrega e troca de formas de valor. Dessa forma, o autor entende que as pesquisas nesse campo podem partir dessa visão inicial e usar a lógica da efetuação (SARASVATHY, 2001) como um meio de entendimento do processo empreendedor de artistas. Essa consideração pode ser aplicada na compreensão do empreendedorismo cultural de maneira mais ampla.

Mas, o que significa empreendedorismo cultural? Esta é uma definição que não se apresenta sem polêmica ou sem dificuldades para uma precisão conceitual (KOLSTEEG, 2013). De forma simplificada, para Kolsteeg (2013), o empreendedorismo cultural ocorre nas organizações culturais ou artísticas que oferecem produtos e serviços que comunicam um valor simbólico e cultural.

De forma semelhante, Banks et al. (2000, p. 453) afirmaram que o empreendedorismo cultural está "diretamente relacionado com a produção de bens e serviços culturais, produtos cujo principal valor é simbólico, derivado da sua função como portadores de significados em imagens, símbolos, sinais e sons". 
Rea (2008), por outro lado, defendeu que o empreendedorismo cultural é uma abordagem multifacetada à cultura como negócio. Este se manifesta por meio da ação de sujeitos inventivos e empreendedores em múltiplas formas de produção cultural. Para Rea (2008), estas ações de produção cultural vão desde a escrita ficcional e tradução em drama, cinema, rádio, até a fabricação de produtos de consumo.

Webb (2014) considera que os artistas que lideram e se engajam em práticas de criação de lugar criativo (creative placemaking) são empreendedores no campo das Artes. A criação de lugares criativos é uma parceria entre os setores público, privado, não lucrativo e da comunidade que moldam estrategicamente as características econômicas, físicas e sociais de um lugar em torno de atividades artísticas e culturais (p. 36). No texto, a autora relata a experiência de três artistas engajados na criação de lugares criativos e aponta como artistas com competências empreendedoras e com um autêntico espírito de cooperação podem ser agentes de mudança em suas comunidades.

Há diversos estudos empíricos que têm adotado o empreendedorismo cultural como campo. Sem intenção de esgotar o tema, devido a limitações de espaço, mas apenas de forma ilustrativa comentam-se alguns deles a seguir.

Smith e Gillett (2015) refletiram sobre sua experiência como membros de uma banda de rock sob uma perspectiva empreendedora. Entres os aspectos mencionados, destacaram-se: a cooperação entre os membros da banda; o compartilhamento de recursos tangíveis e intangíveis; o uso de networking extensivo tanto para viabilizar os produtos musicais da banda quanto na sua comercialização; e um processo coletivo de criatividade.

Martins, Tavares e Rodrigues (2016) analisaram os impactos do discurso sobre empreendedorismo na produção cultural da cidade de Pelotas no Rio Grande do Sul. Com abordagem qualitativa, a partir de entrevistas com sete atores culturais daquela cidade, os resultados demonstraram que houve a necessidade desses atores adotarem técnicas e comportamentos empresariais em paralelo com o trabalho artístico. Isto ficou evidente, inclusive, pela observação das práticas discursivas dos entrevistados que demonstraram a incorporação da linguagem empresarial em seu discurso.

No estudo de Rabelo Neto, Silva e Souza (2016) sobre o campo da produção musical independente foram identificados aspectos centrais do perfil dos empreendedores culturais no 
campo da música: a importância da tecnologia; o conhecimento; o trabalho em equipe; a assunção de riscos; e a visão que compreende a percepção de oportunidades de mercado e compreensão do contexto de negócios.

No campo do cinema, há contribuições significativas para o entendimento do empreendedorismo cultural. Por exemplo, Yamada e Yamashita (2006) analisaram três casos de empresas japonesas bem-sucedidas na produção de filmes e argumentaram que a intenção para inovar é antecedida por uma busca de parceiros. Assim, conforme os casos analisados, a efetivação de uma intenção inovadora ocorreu após o estabelecimento de parcerias. Isto permitiu que as três empresas analisadas desenvolvessem uma posição competitiva sustentável a partir de modelos de negócios inovadores.

Em Jones (2001), encontra-se uma análise longitudinal dos 25 anos iniciais da indústria do cinema nos Estados Unidos. A autora, ao fazer uma análise histórica do surgimento dessa indústria demonstrou como dois tipos de empreendedores - orientados por tecnologia e orientados por conteúdo foram dominantes em períodos distintos dessa trajetória e como usaram estratégias de legitimação, recursos e competências também distintas.

Entre 1895 e 1910, segundo Jones (2001), os empreendedores que tinham uma trajetória original na indústria, usaram estratégias baseadas em patentes para obter desempenhos superiores. No segundo período, entre 1910 e 1920, os empreendedores desenvolveram competências de mercado e contratos de exclusividades com estrelas do cinema, consistentes com suas origens anteriores vinculadas ao comércio e serviços.

Em síntese, o estudo de Jones (2001) evidenciou que estratégias de legitimação podem restringir ou facilitar a entrada de novos competidores em uma indústria. Na era tecnológica (1895-1910), a legitimação regulatória por meio de patentes e processos por desrespeito a patentes inibiu a entrada de novos concorrentes. Por outro lado, na era de conteúdo (19101920), estratégias de legitimação cultural, ao imitar outras áreas artísticas como o teatro, diminuíram as barreiras de entrada da nascente indústria do cinema. Nos dois momentos, as competências desenvolvidas foram distintas. No primeiro, o foco estava em competências que reduzissem custos, enquanto que no segundo as competências envolviam a capacidade de atrai e reter talentos que atraíam público, junto com a verticalização das atividades, comas empresas atuando na produção, distribuição e exibição. 
A história recente do desenvolvimento da indústria cinematográfica da Nova Zelândia foi utilizada por Bruin (2005) para ilustrar o que a autora chamou de Empreendedorismo Multinível. Para tanto, ela se baseou na experiência do setor cinematográfico da região de Auckland demonstrando como o crescimento dessa indústria naquele país é fruto de esforço de empreendedores/artistas, mas também de políticas públicas e ações desenvolvidas no nível do país e da região.

No Brasil, Guerra e Paiva Júnior (2011), em estudo sobre a produção cinematográfica pernambucana, concluíram que:

a ação do empreendedor cultural está relacionada com um esforço de emancipação de grupos profissionais, a melhoria de condições de produção e a absorção de recursos em meio à articulação em rede. Esse perfil de atuação auxilia a (re)discussão dos conceitos de competição e estratégia organizacional sob a perspectiva de um setor produtivo caracterizado pela agregação de pessoas em torno de projetos que expressam aspectos subjetivos de seus parceiros estratégicos (p.84).

\section{Londrix: um empreendimento cultural}

O Festival Literário de Londrina, também conhecido com Londrix, surgiu em 2005 tendo como objetivo a difusão e celebração do universo literário a partir da presença de autores e a promoção dos mais diversos eventos relacionados ao mundo da arte e da literatura, como palestras, debates, workshops, saraus etc., na cidade de Londrina, Paraná. O festival também visa a fomentação da leitura, com um foco em ser um evento democrático, com eventos gratuitos e com grande acessibilidade por parte da população.

Segundo a entrevista de Chris Viana, o próprio surgimento do festival parte de uma colaboração entre um grupo de pessoas:

\footnotetext{
Nos idos 2005, eu, Denise Gentil, Rodrigo Garcia Lopes e o Marcos Losnak, todos amigos, tivemos a mesma ideia separadamente, de desenvolver, produzir um evento que trouxesse autores de outras localidades para estar debatendo com nossos autores. Uma roda de conversa, um evento, que abrangesse todo esse potencial literário que Londrina tem. E realmente essa ideia surgiu separadamente nas nossas cabecinhas, e quem acabou juntando em um evento único foi o Bernardo Pellegrini, porque tanto eu quanto o Rodrigo queríamos fazer um festival literário. O Bernardo promoveu uma reunião, uma conversa e facilmente nós juntamos as ideias e fizemos o primeiro festival literário de Londrina em 2005.
}

A conciliação das ideias separadas e a colaboração, que originou o conceito de um festival único, demonstra como o evento surge a partir de um viés coletivo e colaborativo, 
constatado em muitos estudos sobre o empreendedorismo cultural, como Corá (2016) e Guerra e Paiva Junior (2014), que encontraram no depoimento de empreendedores culturais essa forte colaboração e uma relação próxima entre os colaboradores. Além disso, a fala já expõe como, apesar de não surgir de Viana, a decisão de unir as ideias é uma decisão empreendedora, onde as noções individuais presentes poderiam fortalecer umas às outras e atender à demanda por um evento nos moldes do Londrix dentro da cidade de Londrina, em um esforço de adaptação por parte do grupo.

Essa mesma adaptação pode ser sentida, já numa relação direta com o papel de Chris, quando ela fala sobre a data de realização do festival:

\begin{abstract}
Nós fazemos sempre o evento [...] geralmente em setembro. Nós experimentamos uma vez em dezembro, que não foi muito bom, porque a cidade já tá cheia de eventos devido ao aniversário da cidade, o Natal, então não foi a melhor data. Depois nós trouxemos o festival para o começo do ano, que é esse formato agora que nós estamos adotando e vamos tentar imprimir, o que é bem interessante porque não existem muitos eventos que acontecem no começo do ano e sempre foi um desejo da própria Secretária da Cultura e nós acabamos atendendo e pra gente também fui muito bacana.
\end{abstract}

O conceito cultural do festival, já bem definido em sua formação, fica em segundo plano para a adaptação de qual seria o melhor período para sua realização. E a adaptação vem na prática, durante a administração, há a tentativa e o erro, com o experimento de realizar o festival em dezembro e, em outras edições, passar ele para o início do outro ano. Essa passagem também demonstra outro fator importante nos termos da colaboração, o do papel do ente público, que no caso de Londrix age de forma muito próxima com a gestão do festival em termos financeiros e em escolhas práticas como em relação à data de realização do festival e de outras ações paralelas do festival.

Ao falar dessas ações, as quais chama de "projetos de extensão", Chris afirma:

São projetos de incentivo à leitura que atendem a comunidade. Então nós desenvolvemos o Sarauzinho. Para você ter uma ideia, a gente atende 800 crianças por ano, com distribuição de livros [...] elas vão até um espaço cultural, no caso o cemitério de automóveis, e lá elas participam desse projeto.

Retomando a figura 1, fica claro como o festival literário, além de existir enquanto um festival focado em trazer autores e promover debates especializados, também possui como foco e objetivo a mudança social, outro indicador dele como um caso de empreendedorismo cultural. O projeto Sarauzinho, em específico, ocorre em parceria com a Universidade 
Estadual de Londrina e com entes privados como o Cemitério de Automóveis, outro empreendimento cultural feito por Chris Viana.

Outra ação paralela citada por Chris é o Encantamentos Poéticos, que tem como público alvo a terceira idade:

[...] é um projeto de leitura e de desenvolvimento de memória, sensibilização. A gente trabalha em parceria com a Secretária do Idoso. Atendemos dois centros, o da zona leste e o da zona oeste, com oficinas, e é um projeto muito gratificante.

É perceptível na fala de Chris a importância, para o festival, da ação social, de fazer uso do Londrix para trazer a mudança social, inclusive tornando o projeto mais acessível, realizando-o em duas regiões distintas da cidade. Há a noção da cultura como instrumento da mudança social. E tudo se torna possível a partir de ações empreendedoras, como, nesse caso em específico, a existência da colaboração com o ente público, que aparece como parceiro do festival na realização desses projetos.

A figura 1 também conta com a presença da "mudança institucional" como parte integrante do empreendedorismo cultural. $\mathrm{Na}$ entrevista de Chris, nota-se essa preocupação com a situação institucional no projeto Um Dedo de Prosa, focado em alunos dos colégios estaduais.

Nós temos o Um Dedo de Prosa, que inclusive já ganhou vários prêmios, já viajou pelo Brasil, já fez outras cidades. É um projeto que trabalha temas referentes à literatura dentro do público em formação, que é o aluno, no caso, da Escola Estadual, que é onde temos uma carência maior na questão da leitura, do desenvolvimento de projetos para esse pessoal principalmente do ensino médio.

O empreendimento surgido a partir de Londrix, então, visa responder problemas institucionais da cidade de Londrina, nesse caso um problema relacionado à educação pública da cidade de Londrina, porém ainda com um foco relacionado a um dos motes inicial do festival - a democratização da leitura.

Por fim, Chris cita o Assalto Literário e a Mostra Vídeo Poema, nos quais o fator do empreendedorismo toma forma de diferentes maneiras. Chris aponta o Assalto Literário como um "happening” que ocorre o ano todo, onde há a leitura de poesias e distribuição de livros. Ele ocorre em espaços públicos com concentração de pessoas, como ruas, praças, faculdades e terminais, com objetivo de despertar o interesse do público pela leitura. Assim, o evento serve como forma de criar networking dentro do universo literário e cultural da cidade, além de uma 
plataforma de mudança social a partir da gratuidade e da ponte de acesso que se cria entre a população e a literatura.

Já a Mostra Vídeo Poema tem como foco a diversificação e a experimentação com outras plataformas para a literatura, por meio de uma mostra de poesias em forma de vídeos. A sua simples realização demonstra uma preocupação do festival com a inovação e com novas maneiras de se abordar e expressar dentro da literatura na atualidade. E acaba sendo, em termos gerais, símbolo da forma com que o festival passa a abordar diversas áreas, com os mais diversos objetivos - diversificando o calendário cultural da cidade e as maneiras de se realizar o festival.

Posteriormente na entrevista, Chris Viana discute as formas de financiamento e como o público vem crescendo no festival com o passar dos anos:

Eu sempre brinco que a literatura é a prima pobre de todos os eventos, porque as pessoas não gostam muito de investir na literatura [...]. Então sempre, quando a gente procura o empresariado tem essa especificidade, mas a gente foi rompendo aos poucos até essa questão dos incentivos para a literatura.

Nota-se como, para a realização do festival, há um esforço devido à dificuldade que existe para o seu financiamento. Esse mesmo esforço existe quando se busca o financiamento por meio da parceria com o ente público, a qual é colocada como dúvida por Chris para o futuro:

[...] é um festival que nós não sabemos de agora para diante como vai ser a questão de incentivos. Porque nós temos o PROMIC ${ }^{2}$. Sem o PROMIC nós não conseguiríamos realizar o festival, é um grande incentivador [...] a gente sempre busca e recebe, ou recebia, verba do Ministério da Cultura. Agora mesmo nós fomos contemplados, foi o segundo melhor festival literário do país, [...] recebemos uma verba para a realização do evento que será agora em maio. Com a extinção do MinC nós não sabemos como ficará todo esse cenário, temos que aguardar.

Existe uma busca, então, constante por recursos e uma grande dúvida em relação a eles. O papel de Chris deixa de se resumir a questões de curadoria relacionada ao tema cultural do festival e passa a ser organizacional e administrativo, tornando o evento viável. Nessa fala, percebe-se como isso toma forma na mediação, por parte de Chris, das fontes de financiamento do festival, que são de extrema importância para sua realização. E essa mediação se torna ainda mais importante devido ao cenário de incerteza existente hoje dentro

\footnotetext{
${ }^{2}$ Programa de financiamento a projetos culturias instuído por legislação no município de Londrina
} 
do universo de produções culturais dentro do país - uma situação clara onde o empreendedorismo passa a existir para responder essas questões.

Porém, para Chris, o festival cumpre seu propósito, tanto em termos de alcance popular, quanto em termos de trazer artistas para a cidade de Londrina:

[...] esse ponto eu acredito é o que eu mais possa ressaltar, o crescimento do público. Eu penso como evento de formação, ele tem cumprido seu objetivo. Quanto às palestras, a riqueza estética, sempre são temas muito interessantes, os autores que nós trazemos geralmente ou já são autores que já têm um certo reconhecimento de público e crítica, mas parece que o Londrix serve como um termômetro, vários autores que trouxemos vêm em um ano e no outro ele é indicado para algum prêmio, ou o Jabuti ou algum outro prêmio.

\section{Considerações finais}

Apesar de ainda ser um campo de estudos considerado novo, as contribuições para o estudo do empreendedorismo cultural já podem ser consideradas significativas, tanto dentro e fora do Brasil. Os estudos de caso, com base em entrevistas e diálogos com os atores culturais, se revelam de extrema importância para esse desenvolvimento do tema, criando uma ponte entre a teoria e a realidade e propondo novas possibilidades e abordagens para a teoria, novos caminhos a se percorrer.

A entrevista disponível online de Chris Viana, do Festival Literário de Londrina, aponta essas tendências. A partir de uma fala curta sobre a história, realização, projetos e dificuldades do evento, percebe-se diversos caminhos apontados pela teoria e que são seguidos por ela: o forte viés colaborativo, a busca por recursos, as parcerias público-privadas e a preocupação com questões sociais e institucionais.

Considerando a visão de uma autora como Webb (2017), Chris participa ativamente da criação de um lugar criativo, no qual o forte teor criativo e cooperativo usado em atividades ligadas aos mundos culturais e artísticos existe em prol da mudança social, funcionando como um agente para tal. Essa visão corrobora, também, a visão antropológica do empreendedorismo cultural, apontado por Albinsson (2017), no qual o empreendedorismo cultural se utiliza das ferramentas encontradas dentro de uma cultura específica e age dentro dessa cultura, muitas vezes com a preocupação com a questão social.

Outro viés para análise se encontra na simples realização do festival enquanto produto artístico e cultural. Na fala de Chris, é possível apontar diversas técnicas e comportamentos 
empresariais tomados por parte dela e dos organizadores do festival, o mais evidente deles no que tange aos recursos para sua realização. A preocupação com o crescimento do público, também, aponta como o evento precisa atingir seus objetivos, e Chris comenta ações que ajudaram o Londrix nessa questão, como por exemplo parcerias com a Universidade Estadual de Londrina e abusca de financiamento público participando de ditais em nível municipal e federal.

É possível, então, a partir da análise da fala de empreendedores culturais como Chris, verificar como o objeto de estudo e as conclusões de estudos teóricos e empíricos podem se replicar em diversos casos, e como o fenômeno do empreendedorismo cultural possui forte presença dentro da economia cultural da atualidade, que exige habilidades muito diversas, além da esfera artística, dos atores dentro dela.

\section{Referências}

ALBINSSON, S. What is so "cultural" about cultural entrepreneurship. The Journal of the Economic \&Business History Society v. 35, n. 1, p. 366-390, 2017.

BANKS, M.; LOVATT, A.; O`CONNOR, J.; RAFFO, C. Risk and trust in the cultural industries. Geoforum, n. 31, p. 453-464, 2000.

BENDASSOLLI, P. F. et al. Indústrias criativas: definição, limites e possibilidades. Revista de Administração de Empresas, São Paulo, FGV, v. 49, n. 1, p. 10-18, 2009.

BENDASSOLLI, P. F.; Wood Júnior, T. O paradoxo de Mozart: carreiras nas indústrias criativas. Organizações \& Sociedade, Salvador, UFBA, v. 17, n.53, p. 259-277, 2010.

BRAGA, W. D. Novas identidades para o novo mundo do trabalho através da Cultura: o velho mantra do capitalismo revisitado. Revista Eptic, v. 17, n. 1, p. 218-235, 2015.

BRUIN, A. de Multi-level entrepreneurship in the creative industries. New Zealand's screen production industry. The International Journal of Entrepreneurship and Innovation, v. 6, n. 3, p. 143-150, 2005.

CORÁ, M. A. J. Empreendedores criativos: uma análise sobre o trabalho na cultura. Revista Interdisciplinar de Gestão Social, v. 5, n. 2, p. 71-89, 2016.

DE MARCHI, L. Do marginal ao empreendedor. Transformações no conceito de produção fonográfica independente no Brasil. Eco-Pós, v. 9, n. 1, p. 121-140, 2006. 
DIMAGGIO, P. Cultural entrepreneurship in nineteenth-century Boston: the creation of an organizational base for high culture in America. Media, Culture and Society, v. 4, n. 1, p. 3350, 1982a.

DIMAGGIO, P. Cultural entrepreneurship in nineteenth-century Boston, part II: the classification and framing of American art. Media, Culture and Society, v. 4, n. 4, p. 303-322, $1982 \mathrm{~b}$.

ELLMEIER, A. Cultural Entrepreneurialism: On the Changing Relationship between the Arts, Culture and Employment, International Journal of Cultural Policy, v. 9, n. 1, p. 3-16, 2003.

ENHUBER, M. How is Damien Hirst a cultural entrepreneur? Artivate: A Journal of Entrepreneurship in the Arts, v. 3, n. 2, p. 3-20, 2014.

GANGI, J. J. Towards consensus: suggested foundational building blocks for arts entrepreneurship research and pedagogy. Artivate: A Journal of Entrepreneurship in the Arts, v. 6, n.1, p. 46-62, 2017.

GIMENEZ, F. A. P. Empreendedorismo: uma bibliografia de artigos publicados em periódicos brasileiros. Curitiba: do Autor, 2017.

GUERRA, J. R. F.; PAIVA JÚNIOR, F. G. Empreendedorismo cultural na produção cinematográfica: a ação empreendedora de realizadores de filmes pernambucanos. Revista de Administração e Inovação, v. 8, n. 3, p. 78-99,2011.

HAUSMANN, A.; HEINZE, A. Entrepreneurship in the cultural and creative industries: insights from an emergent field. Artivate: A Journal of Entrepreneurship in the Arts, v. 5, n. 2, p. 7-22, 2016.

JONES, C. Co-evolution of entrepreneurial careers, institutional rules and competitive dynamics in American film, 1895-1920. Organization Studies, v. 22, n. 6, p. 911-944, 2001.

KIRSCHBAUM, C. et al Indústria Criativa no Brasil. São Paulo: Atlas, 2009.

KLAMER, A. Cultural Entrepreneurship. The Review of Austrian Economics, v. 24, n. 2, p. 141-156, 2011.

KOLSTEEG, J. Situated cultural entrepreneurship. Artivate: A Journal of Entrepreneurship in the Arts, v. 2, n. 1, p. 3-13, 2013.

LIPARTITO, K. Culture and the Practice of Business History. Business and Economic History, v. 24, n. 2, p. 1-42, 1998. 
LOUNSBURY, M; GLYNN, M. A. Cultural Entrepreneurship: Stories, Legitimacy, and the Acquisition of Resources. Strategic Management Journal, v. 22, n. 6-7, p. 545-564, 2001.

MARTINS, M. I.; TAVARES, L. F.; RODRIGUES, M. S. O discurso do empreendedor cultural e seus reflexos na cena alternativa da cidade de Pelotas (RS). Políticas Culturais em Revista, v. 9, n. 1, p. 210-243, 2016.

MICHETTI, M.; BURGOS, F. Fazedores de cultura ou empreendedores culturais? Precariedade e desigualdade nas ações públicas de estímulo à cultura. Políticas Culturais em Revista, v. 9, n. 2, p. 582-604, 2016.

OLIVEIRA, T. B. Protagonismo cultural e empreendedorismo urbano: encruzilhadas da Lei de Fomento ao Teatro Em São Paulo. Políticas Culturais em Revista, v. 1, n. 8, p. 239-254, 2015 .

RABELO NETO, A.; SILVA, A. S. L. da; SOUZA, A. M. R. de O perfil empreendedor no mercado de música independente. Caderno Profissional de Administração - UNIMEP, v. 6, n. 1, p. 68-86, 2016.

REA, C. G. Comedy and cultural entrepreneurship in Xu Zhuodai's "Huaji Shanghai". Modern Chinese Literature and Culture, v. 20, n. 2, p. 40-91, 2008.

SARASVATHY, S. D. Causation and effectuation: toward a theorical shift from economic inevitability to entrepreneurial contigency. Academy of Management Review, v. 26, n. 2, p. 243-263, 2001.

SCHUMPETER, Joseph A. The theory of economic development. Cambridge, Harvard University. 1957.

SMITH, G. D.; GILLETT, A. Creativities, innovation, and networks in garage punk rock: a case study of The Eruptörs. Artivate: A Journal of Entrepreneurship in the Arts, v. 4, n. 1, p. 9-24, 2015.

WEBB, D. Placemaking and social equity: expanding the framework of creative placemaking. Artivate: A Journal of Entrepreneurship in the Arts, v. 3, n. 1, p. 35-48, 2014.

YAMADA, J-I.; YAMASHITA, M. Entrepreneurs' intentions and partnership towards innovation: evidence from the Japanese film industry. Creativity and Innovation Management, v. 15, an. 3, p. 258-267, 2006. 